\title{
Steady State Counterbalance Valve Modeling with the Influence of Synthetic Ester Oils Using CFD
}

\author{
J.H. Jakobsen ${ }^{1}$ M.R. Hansen ${ }^{2}$ \\ ${ }^{1}$ Mechatronics Group, University of Agder, N-4898 Grimstad, Norway. E-mail: jannik.jakobsen@uia.no \\ ${ }^{2}$ Mechatronics Group, University of Agder, N-4898 Grimstad, Norway. E-mail: michael.r.hansen@uia.no
}

\begin{abstract}
This study looks in details at the effects of synthetic esters being applied to a counterbalance valve from the perspective of a system engineer. There is limited literature on the subject of applied synthetic esters and as such limited unbiased sources for information. This creates reluctance against the use of these fluids in sectors and regions with no prior experience and knowledge of what to expect. This study expands the applied literature by investigating a commercially available valve using commercial oils, a basic synthetic ester, a fully saturated synthetic ester and a typical mineral oil type for benchmarking. The investigation is based on both computational fluid dynamics and experiments and is performed at 20,40 and $60^{\circ} \mathrm{C}$. The product is a steady-state valve model including fluid dynamics and a parameter-dependent Coulomb friction. The CFD model reveals minimal oil type dependence in the resulting fluid dynamics model with flow forces and discharge coefficient being the same for mineral oil and esters. The experiments show that the esters primarily produce different levels of hysteresis with up to $40 \%$ less and $15 \%$ more hysteresis. The friction investigation showed that the relationship between hysteresis and pilot pressure was different for all oil types, and that the relationship between hysteresis and temperature was similar for all oil types. With full knowledge of mineral oil and the oil specific knowledge of the hysteresis and pilot pressure relationship at a single temperature, ester hysteresis was predicted with better than $88 \%$ accuracy across the three temperatures.
\end{abstract}

Keywords: Counterbalance valve, Valve friction, CFD, Synthetic Esters

\section{Introduction}

Synthetic esters are already being used in hydraulics, but there is limited academic literature on the subject, which forces engineers to rely on experience and the limited information available from suppliers. This leads to a reluctance against use in regions and sectors without prior experience. This study aims to reduce uncertainties with the use of synthetic esters in hydraulics, specifically regarding the behavior of counterbalance valves, CBVs.

Why synthetic esters? Hydraulics is often used in mobile machinery or stationary equipment where a spill will end up in nature. Spills are inevitable and the simplest way of dealing with the environmental implications is therefore to replace the source of the spill, the hydraulic oil. Synthetic ester blends can be biobased, biodegradable and have acceptable bio-toxicity, that reduce the impact of a spill to an acceptable level. Besides being more environmentally friendly, synthetic esters can handle the demands of high-performance hydraulics and is currently the only commercial bio-based and environmentally friendly fluid to do so. The esters are known to have properties similar to the standard mineral oils. The main properties of interest in this study are those directly influencing valve behavior through fluid dynamics or friction. Table 1 and Ta- 
ble 2 display the density and viscosity of the two esters tested alongside the properties of the tested mineral oil (ISO-HV) of the same viscosity grade. Two types of synthetic esters are chosen: fully saturated (HEES+) and regular (HEES). Both have viscosity and density within $10 \%$ of $\mathrm{HV}$. The table values are in line with the values of other synthetic esters (Radhakrishnan, 2003).

Table 1: Oils used for testing,(Shell, 2013),(Statoil, 2013a),(Statoil, 2013b).

\begin{tabular}{llc}
\hline Oil type & Product & $\rho\left[\mathrm{kg} / \mathrm{m}^{3}\right]$ \\
\hline HV & Shell Tellus S2 V46 & 872 \\
HEES & Statoil Hydraway & \\
& BIO SE 46 & 921 \\
HEES+ & Statoil Hydraway & \\
& SE 46 HP & 923 \\
\hline
\end{tabular}

Table 2: Viscosity of the tested oils. $\nu_{x}[\mathrm{cSt}]\left(\nu\right.$ at $\left.\mathrm{x}^{\circ} \mathrm{C}\right)$. Values at $-20,40$ and $100^{\circ} \mathrm{C}$ are from data sheets. $20^{\circ} \mathrm{C}$ and $60^{\circ} \mathrm{C}$ are calculated using the Uddebuhle-Walther equation and the two nearest data sheet values.(Shell, 2013),(Statoil, 2013a),(Statoil, 2013b)

\begin{tabular}{lccccc}
\hline Oil type & $\nu_{-20}$ & $\nu_{40}$ & $\nu_{100}$ & $\nu_{20} *$ & $\nu_{60} *$ \\
\hline HV & 2350 & 46 & 7.9 & 116 & 19.3 \\
HEES & 1450 & 47 & 9.5 & 108 & 21.3 \\
HEES+ & 2179 & 45.3 & 8.0 & 113 & 19.3 \\
\hline
\end{tabular}

The only properties listed in the ester data sheets related to tribology are scuffing tests, which cannot be directly related to friction and limited literature on the subject exists. (Zulkifli et al., 2013), (Martins et al., 2006), (Azushima et al., 2009) and (Kržan and Vizintin, 2004) all test specific friction aspects with unnamed synthetic esters but it is unclear, how they relate to the chosen ester oils. (Jakobsen and Hansen, 2018) test the same oils but on a very different valve type. Based on available literature it is therefore unclear, what is to be expected with regards to synthetic ester friction in CBVs. It should be noted that the valve seals are of the material fluoropolymer elastomer, FPM, as recommended for dynamic seals when using esters.

Why counterbalance valves? Generally, there is very little available research on esters at the hydraulic component level. (Jakobsen and Hansen, 2018) have looked at pressure compensated directional control valves and (Remmelmann, 1999) and (Enekes and Murrenhoff, 2010), looked at axial piston machines, but most hydraulic components are left without publica- tions. Counterbalance valves are different from the pressure compensated directional control valves, PCDCVs, investigated in (Jakobsen and Hansen, 2018), in that seals are used to enable leak-tight load-holding, and the valves are typically characterized by high seal friction (Handroos and Halme, 1996). Characterizing the effect of esters on CBVs, therefore, covers a different part of the valve spectrum. The CBV is, at the same time, an important valve in load carrying applications, where it provides fully mechanical load-holding, overload protection, and acts as a line rupture safety valve. Combining the $\mathrm{CBV}$ with $\mathrm{PCDCVs}$ often result in systems prone to oscillations and accurate modeling of the valve is important for predicting undesired behavior and for finding viable solutions.

Why computational fluid dynamics? Simpler models are not accurate enough to allow a clear separation of fluid dynamics and friction. Separating the two phenomena is essential in characterizing and generalizing the valve behavior and therefore the broader value of this study.

The study is made for the system engineers and hopes to answer the following questions:

- How is the CBV with synthetic ester behavior different from the CBV with oil type HV?

- How are the differences modelled?

- What information is needed to describe the differences?

\section{Model}

The CBV is modeled with the intent to identify the link between physical properties of the valve and oil and the valve behavior obtained from experiments. This is done in order to determine which parameters need attention when modeling with multiple oil types.

The study is based on a commercial 3-port CBV. It can be characterized as a restrictive CBV with nonaxisymmetric flow access to its main restriction. The focus is on the valves load-holding function, where the valve acts as a piloted-open-relief valve. During loadholding, flow is restricted in passing from load-side (red region, see Figure 1) to the back-side (blue region). Figure 1 depicts the closed valve with spool position $\mathrm{u}=0 \mathrm{~mm}$. The check element is resting against a stop (not depicted), and it does not move during load-holding. If the spool moves to the right $(\mathrm{u}>0 \mathrm{~mm})$ the valve opens, and oil will flow across the gap between the check element and the spool called the main restriction. If and to what degree the spool moves is determined by the sum of forces on the spool. The 
load pressure, $p_{L}$, and the pilot pressure, $p_{P}$, will produce valve opening forces while $p_{B}$ and a spring (not depicted) will produce valve closing forces. Figure 1 also shows the pressure regions and the effective spool areas, on which they act. The actual values for the spool areas can be found in Table 3 .

Table 3: Measured effective cross-sectional spool areas,

$\alpha=$\begin{tabular}{lc}
\multicolumn{2}{l}{$A_{P} / A_{L}=2.72}$. \\
\hline Parameter & Value \\
\hline$A_{L}$ & $10.7 m^{2}$ \\
$A_{L}$ & $\alpha A_{L}$ \\
$A_{B}$ & $(\alpha+1) A_{L}$ \\
\hline
\end{tabular}

The pressures $p_{L}, p_{P}$ and $p_{B}$ will be evenly distributed throughout their respective regions, when the valve is closed. But once the valve is open fluid dynamics dictates a different distribution especially in high speed and momentum changing regions. The difference between the force produced by a uniform pressure distribution and the actual force is the flow force. The non-axisymmetric flow access of the main restriction of the studied valve makes it so that the flow forces on the valve are relatively large. Modeling fluid dynamics is therefore particularly important on this valve.

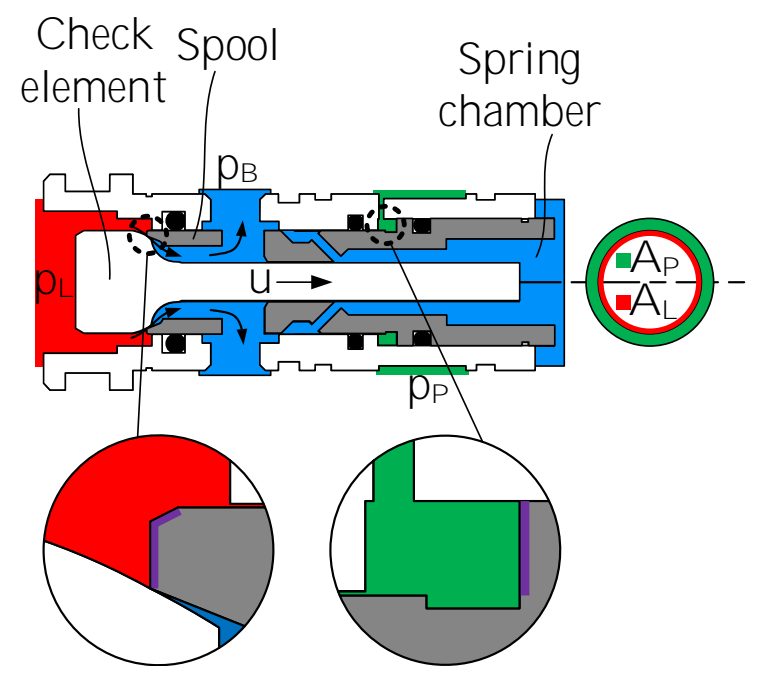

Figure 1: A section view of the CBV, with pressure indications, and effective cross-sectional areas. Note scales on the two zooms are not the same. The surfaces marked with purple indicate the effective spool areas in the projection.

Figure 2 shows the limited access to the main restriction. Section $\mathrm{G}$ only allows the oil to pass through the top and bottom of the cross-section. This results in an uneven pressure distribution along the cross-section of the main restriction and the AL surface, and it reduces the flow through the main restriction.
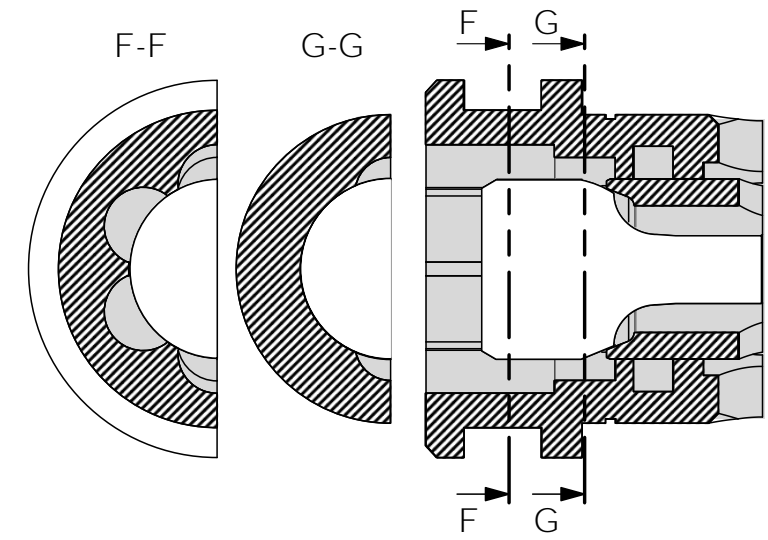

Figure 2: Valve cut-out illustrating the lack of axisymmetry in the restricted flow inlet.

\subsection{Model Components}

The objective is to model the valve flow through main restriction at steady state. The flow is determined by the pressure on either side of the restriction, $p_{L}$ and $p_{B}$, the spool position, $\mathrm{u}$, the geometry of the restriction, the oil type and the temperature.

$$
q=f\left(p_{L}, p_{B}, u, \gamma, \tau\right) .
$$

Where, $\gamma$ is the chosen oil type for the system, which influences the fluid dynamic properties as well as tribological properties, $\tau$ is the temperature, which mainly influences the state of the fluiddynamic properties and tribological properties.

In this study, CFD is used to map q as a function of the 4 independent variables $\Delta p, \mathrm{u}, \gamma$ and $\tau$.

$$
q=q_{\operatorname{sim}}(\Delta p, u, \gamma, \tau)
$$

Where $\Delta p=p_{L}-p_{B}$.

$p_{B}$ is a function of $\mathrm{q}$ and $\tau$ in the test setup and therefore not an independent variable in the test. It does, however, have some influence on the flow and is included in the CFD simulations.

The spool position, $\mathrm{u}$, is determined by the three forces acting on the spool, the fluid force, $f_{f l}$, the friction force $f_{\mu}$ and the spring force, $f_{s p r}$.

$$
\sum f_{\text {spool }}=f_{f l}-f_{\mu}-f_{s p r} .
$$

The spring force is given by (4)

$$
f_{s p r}=F_{c r}+K_{f} u \text {. }
$$


Where $F_{c r}$ is the crack force, the spring force at $\mathrm{u}=0 \mathrm{~mm}$ and $K_{f}$ is the spring constant.

The fluid force is the sum of forces from the pressure regions on the surfaces of the spool. It is found using the same CFD simulation as for $\mathrm{q}$. The flow in some areas of the valve is however very small, and the pressure distribution is assumed uniform, and it is not included in the simulation. The forces from these areas are added separately as the product of the pressures and the respective effective areas:

$$
f_{f l}=f_{s i m}(\Delta p, u, \gamma, \tau)-p_{B} A_{s 3}+p_{P} A_{p} .
$$

Where $A_{s 3}$ is the effective area of the spring chamber of Figure 1.

The friction force is produced by friction between spool, seals and spool track. (Liu and Bo Xie, 2014) used a simple Coulomb friction model, and (Handroos and Halme, 1996) identified a $p_{L}$ dependent Coulomb friction. Both studies were on other CBVs. This study suggests a Coulomb friction dependent on $p_{P e}, \gamma$ and $\tau$ for the fully developed friction:

$$
f_{\mu}=f_{\mu 0}\left(p_{P e}, \gamma, \tau\right) .
$$

$p_{P e}$ is the effective pilot pressure defined as:

$$
p_{P e}=p_{P}-p_{B} .
$$

The variation of $p_{B}$ throughout the tests due to variation in $\mathrm{q}$ and temperature was 1.2 to 7.3 bar. $p_{P}$ was therefore adjusted to reduce the impact of $p_{B}$ on comparisons across temperature and flow. The study also shows, that the actual friction develops as the spool moves from a standstill, and that a more complex model would be needed, if perfect friction tracking was the objective. The Coulomb friction model was however sufficient for evaluating the maximum hysteresis.

\section{CFD Model}

The $q_{\text {sim }}$ and $f_{\text {sim }}$ maps are based on a set of CFD simulations. Solutions are found for discrete values of $\mathrm{q}, \mathrm{u}, \gamma, \tau$ and interpolation is then used to create the continuous maps used in the model. The meshes used in the CFD simulations are generated in Siemens Star CCM+, and are run using the commercial software package Ansys Fluent. The mesh geometry is based on measurements from a precision calliper and macro photography and precision tolerances down to $\pm 0.01 \mathrm{~mm}$ were achieved. One mesh is created for each simulated value of $u$.

$$
u_{\text {sim }} \in\{0.05,0.08,0.10,0.13,0.16,0.20,0.63\} .
$$

The number of cells in each mesh varies depending on the gap size of the main restriction and therefore $u$. At small $\mathrm{u}$ the gap becomes so narrow that more cells are needed to resolve the velocity profile across the width. The meshes contain between 1.6 to $4.3 \mathrm{M}$ cells and is a polyhedral mesh with 6 prism layers.

The CFD model is based on the model components chosen by (Valdés et al., 2014) for simulation of flow through a ball valve. The main components are shown in Table 4 . The shear-stress transport $\kappa-\omega$ model combines the two most popular RANS-based (Reynoldsaveraged NavierStokes equations) turbulence models using the $\kappa-\epsilon$ model in the far-field and the $\kappa-\omega$ model in near-wall-regions. The cavitation is treated as vapourization, and the Schnerr-Sauer model is a cavitation model based on the Rayleigh-Plasset equation, which models the growth of a fixed number of bubbles per volume as a function of the difference between the pressure and the vapour pressure, $p_{v a p}$. The cavitation will however come from two sources, dissolved air released at $1.0 \mathrm{bar}$, and vapourization of the oil at a lower pressure depending on the oil type. HV has a vapour pressure around 0.3 bar. Simulations for $\mathrm{HV}$ at $\mathrm{u}=0.1 \mathrm{~mm}, \mathrm{q}=12 \mathrm{l} / \mathrm{min}$ and $40^{\circ} \mathrm{C}$ were run with a vapour pressure of $0.3 \mathrm{bar}$ and $1.0 \mathrm{bar}$ with less than $0.25 \%$ difference on $\Delta p$. For the sake of simplicity, $p_{\text {vap }}=1.0 \mathrm{bar}$ is chosen for the simulations. Using the cavitation model caused up to $9 \%$ higher $\Delta p$ and $24 \%$ higher $f_{\text {sim }}$ when compared to the same model with no cavitation component and a fixed minimum pressure of 0bar. The homogeneous mixture model is the simplest multi-phase model available. It is frequently used for cavitation in hydrodynamics (Ferrari, 2017). The

Table 4: CFD model components

\begin{tabular}{ll}
\hline Model type & Model \\
\hline Turbulence & SST $\kappa-\omega$ \\
Cavitation & Schnerr-Sauer \\
Multi-phase & Mixture \\
\hline
\end{tabular}

simulations are run for all three oils HV, HEES and HEES + and the three temperatures 20,40 and $60^{\circ} \mathrm{C}$ at constant flow between 1 and $12 \mathrm{l} / \mathrm{min}$. The temperatures influence on density is ignored and kept at the values of Table 1, as no other densities are available in the datasheets. Viscosity is adapted to temperature in accordance with Table 2 . The resulting $q_{\text {sim }}$ and $f_{\text {sim }}$ maps can be seen in Figure 7, 8, 9 and 10.

\section{CFD analysis of the valve}

The valves flow force and the discharge coefficient of the main restriction, $C_{d}$, are analysed to identify, how the fluid dynamics of the valve change with tempera- 


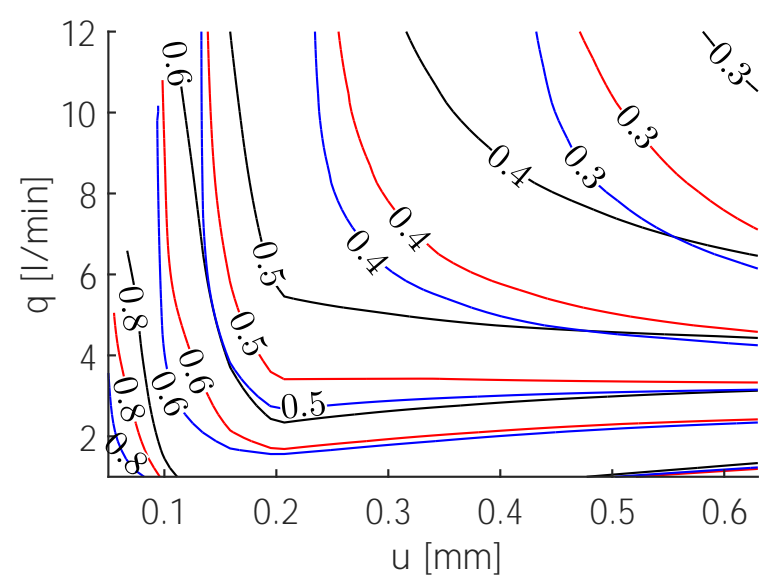

Figure 3: $\alpha_{A L}(\mathrm{u}, \mathrm{q})$ for $\mathrm{HV}$ at 20(black), 40(red), and $60^{\circ} \mathrm{C}$ (blue)

ture and oil type. The flow force is depicted using the ratio $\alpha_{A L}(\mathrm{u}, \mathrm{q})$ in Figure 3. The figure shows contours based on interpolation of $\alpha_{A L}$ calculated for each simulation. $\alpha_{A L}(\mathrm{u}, \mathrm{q})$ is the ratio of CFD calculated forces on the $A_{L}$ surface to the force produced by assuming load pressure on the same surface.

$$
\alpha_{A L}(u, q)=\frac{f_{\text {sim.AL }}}{p_{L} A_{L}} .
$$

$\alpha_{A L}<1$ for all values of $\mathrm{q}$ and $\mathrm{u}$. The simulated force, $f_{\text {sim.al }}$, is, therefore, less than that produced by a uniform $p_{L}$ distribution. $\alpha_{A L}$ is for high flow mostly a function of $\mathrm{u}$, and it is for large $\mathrm{u}$ mostly a function q. For $0.05 \mathrm{~mm}<\mathrm{u}<0.33 \mathrm{~mm}$, which covers most of the workspace (see Section 7), $\alpha_{A L}$ is mostly a function of $\mathrm{u}$ and span the values 0.4 to 0.8 . $\alpha_{A L}<0.3$ at high flow and large $\mathrm{u}$. While the $A_{L}$ surface is not the only surface to be effected by a flow force, the flow force on the other surfaces are significantly smaller and $\alpha_{A L}$ is therefore a good representation of the flow force effecting the valve. It follows, that the flow force affecting the valve reduces the opening force from the load pressure by between $20-60 \%$ in the primary workspace and could potentially reduce it by more than $70 \%$. $\alpha_{A L}$ reduces with increasing temperature but the trends of the above remain. Figure 4 shows the $\alpha_{A L}$ contours calculated for all three oil types at $40^{\circ} \mathrm{C}$. The flow force does not change significantly with oil type and the contours of all three oil types are very similar. $\alpha_{A L}$ for $\mathrm{HV}$ is a bit higher but not significantly so. Simulations for the temperatures 20 and $60^{\circ} \mathrm{C}$ (not shown) also showed very little difference on flow forces produced by synthetic esters and mineral oil.

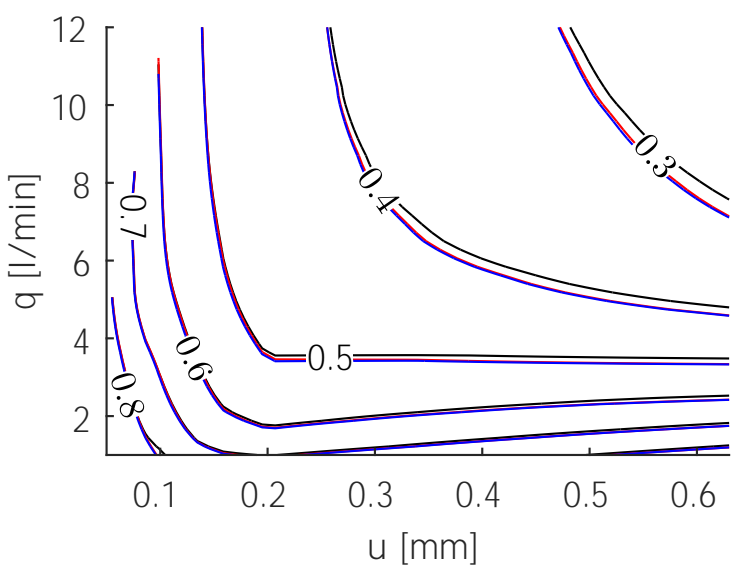

Figure 4: $\alpha_{A L}(\mathrm{u}, \mathrm{q})$ for $\mathrm{HV}($ black $)$ HEES(red) $\mathrm{HEES}+($ blue $)$ at $40^{\circ} \mathrm{C}$

$C_{d}$ is calculated as follows:

$$
C_{d}=\frac{q}{A_{d}(u) \sqrt{\frac{2}{\rho} \Delta p}} .
$$

Where $A_{d}(\mathrm{u})$ is the cross-sectional area across the gap of the main restriction, which is close to proportional to u. Figure 5 shows $C_{d}$ as a function of $\mathrm{u}$ and Re for $\mathrm{HV}$ at 20,40 and $60^{\circ} \mathrm{C}$. The figure shows contours based on interpolation of $C_{d}$ calculated for each simulation. All three temperature align when plotted as a function of Re, and it shows that $C_{d}$ is a function of Re rather than q. As a general trend $C_{d}$ is primarily dependent on $\mathrm{u}$ above $\operatorname{Re}>400$ and mostly dependent on $\mathrm{q}$ for $\operatorname{Re}<200$. For the primary workspace $0.05 \mathrm{~mm}<\mathrm{u}<0.33 \mathrm{~mm} C_{d}$ depends on both and $C_{d}$ varies from 0.25 to 0.75 . The figure depicts a strong temperature dependency. The flow corresponding to Re for each of the three temperatures is seen on the right axis. It shows that all $\mathrm{q}$ at $40^{\circ} \mathrm{C}$ are below the $\mathrm{Re}=400$ mark and that all $\mathrm{q}$ are below $\mathrm{Re}=200$ for $20^{\circ} \mathrm{C}$, and $C_{d}$ is therefore highly q dependent at these temperatures, whereas for $60^{\circ} \mathrm{C}$ a large part of the workspace is in the primarily $u$ dependent region.

The oil type has little influence on the $C_{d}$ factor as seen in Figure 6. The figure includes all three oil types but only for $40^{\circ} \mathrm{C}$. The differences between the oil types are very small for $40^{\circ} \mathrm{C}$, but this is also true for $20^{\circ} \mathrm{C}$ and $60^{\circ} \mathrm{C}$ (not shown).

\section{CFD results}

The components needed for the valve model $q_{\text {sim }}$ and $f_{\text {sim }}$ are depicted in Figure 7, 8, 9 and 10. $\Delta p$ as a function of $q_{\text {sim }}$ is shown in Figure 7 and 8, and $f_{\text {sim }}$ as a function of $\mathrm{q}$ is shown in Figure 9 and 


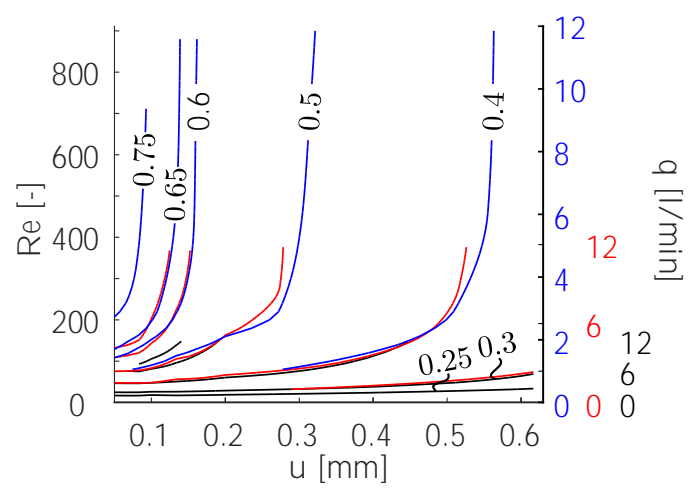

Figure 5: $C_{d}(\mathrm{u}, \mathrm{Re})$ for $\mathrm{HV}$ at 20(black), 40(red), and $60^{\circ} \mathrm{C}$ (blue)

10. The overall trends of $\Delta p\left(q_{\text {sim }}\right)$ and $f_{\text {sim }}\left(q_{\text {sim }}\right)$ are the same as the force on the valve and the pressure difference is naturally linked. Figure 7 shows $\Delta p\left(q_{\text {sim }}\right)$ for $\mathrm{HV}$ at all three temperatures. Each line is produced by 4-5 simulations with the same $\mathrm{u}$. $u \in\{0.05,0.08,0.10,0.13,0.16,0.20,0.63\} \mathrm{mm}$ starting at $0.05 \mathrm{~mm}$ in the upper left portion of the graph ending at $0.63 \mathrm{~mm}$ in the lower right. Each colour represents a different temperature. The figure illustrates what is to be expected, $\Delta p$ increases with $\mathrm{q}$ and reduces with u. The figure also shows significant changes with temperature. Figure 8 shows all three oils at $40^{\circ} \mathrm{C}$. The differences between oil types are very small. Figures 9 and 10 of $f_{\text {sim }}(q)$ show the same result. The CFD results overall show very little difference with oil type, and the choice between mineral oil and ester has a negligible effect on the simulated $C_{d}$, flow force and ultimately the $q_{\text {sim }}$ and $f_{\text {sim }}$ maps. The predicted fluid dynamics of esters and $\mathrm{HV}$ is similar, to the point that it can be argued that simulation for one oil covers the others.

There was a difference of $6 \%$ in density and $10 \%$ in viscosity $\left(\right.$ at $60^{\circ} \mathrm{C}$ ) between the oil types, and any oil within a similar density and viscosity range would yield the same results.

\section{Test setup}

The test circuit is shown in Figure 11. The overall objective is to model and predict the flow through the valve. For that purpose $\mathrm{q}$ was measured together with $p_{L}, p_{B}, p_{P}$ and $\tau$. Each test consists of a sequence where $q$ was controlled and ramped up from $01 /$ min to $12 \mathrm{l} / \mathrm{min}$ then down to $0 \mathrm{l} / \mathrm{min}$ again while $p_{P e}$ was kept constant. The control of $\mathrm{q}$ and $p_{P e}$ was both done using pressure compensated directional proportional control valves, PCDPCV. q was directly controlled while $p_{P e}$

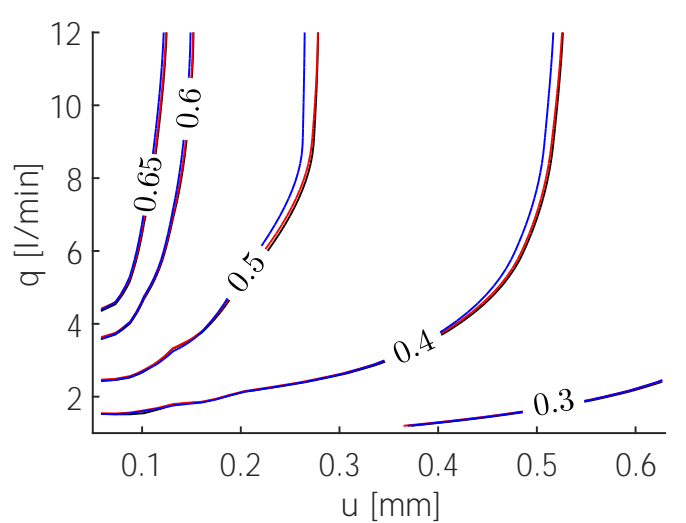

Figure 6: $C_{d}(\mathrm{u}, \mathrm{Re})$ for $\mathrm{HV}($ black $)$ HEES(red) HEES+(blue) at $40^{\circ} \mathrm{C}$

was controlled by adjusting $p_{P}$ using a PCPDCV in series with two adjustable orifices. The test was performed in a small closed circuit where oil exchange was manageable. This meant that the hydraulic power supply was limited to $200 \mathrm{bar}$ and $15.5 \mathrm{l} / \mathrm{min}$, and that the tests were limited to $180 \mathrm{bar}$ and $12 \mathrm{l} / \mathrm{min}$. The flow sensor was an encoder based gear sensor with flow dependent response time, and $\mathrm{q}<1 \mathrm{l} / \mathrm{min}$ has not been included in the data as the response time was unacceptable.

\section{Data}

The data is plotted as four figures of $\Delta p$ as a function of q. One figure with $\mathrm{HV}$ and all temperatures to showcase the difference with temperature Figure 14, and three figures with the three oil types at a single temperature to find similarities and differences between the oil types, Figures 15, 16 and 17.

Each of the Figures 14, 15, 16 and 17 displays a collection of several data sets. The data sets each contain a forward curve and a return curve from a test with a given $p_{P e}$. Figure 12 shows a sketch of a typical CBV plot for single oil and a single temperature. The black dashed line represents the behavior of the valve if no friction is present, in that case, the valve opens $(\mathrm{q}=0 \mathrm{l} / \mathrm{min})$ at a $\Delta p_{0}$ determined by the precompression of the spring and the pilot pressure:

$$
\Delta p_{0}=\frac{f_{c r}}{A_{L}}-\alpha \cdot p_{P e} .
$$

However, due to friction more $\Delta p$ is needed to open the valve and the actual $\Delta p(\mathrm{q})$ curve starts at the beginning of the higher red curve instead (point $[\mathrm{A}]$ ). From here $\Delta p$ steadily increases with $\mathrm{q}$ along the red curve until the turning point where q starts to decrease (point $[\mathrm{B}]$ ) and follows the blue curve back to $\mathrm{q}=0 \mathrm{l} / \mathrm{min}$ 


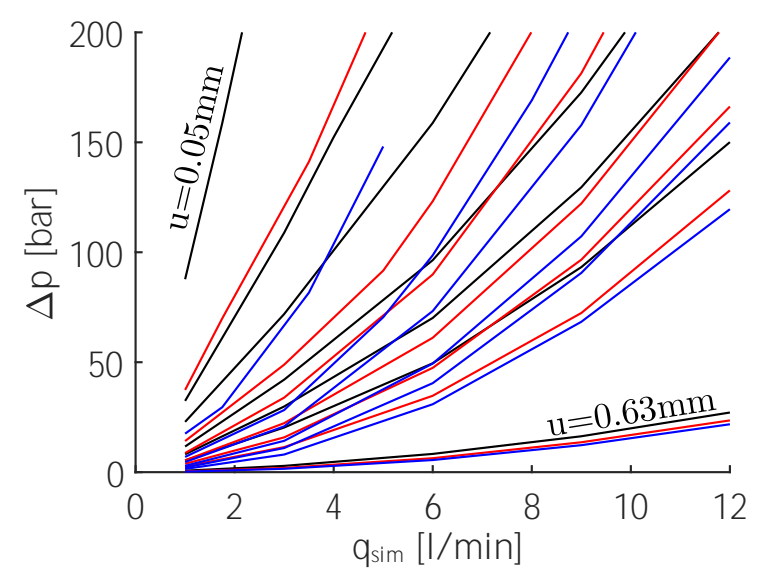

Figure 7: $\Delta p\left(q_{\text {sim }}\right)$ for HV at 20(black), 40(red), and $60^{\circ} \mathrm{C}$ (blue)

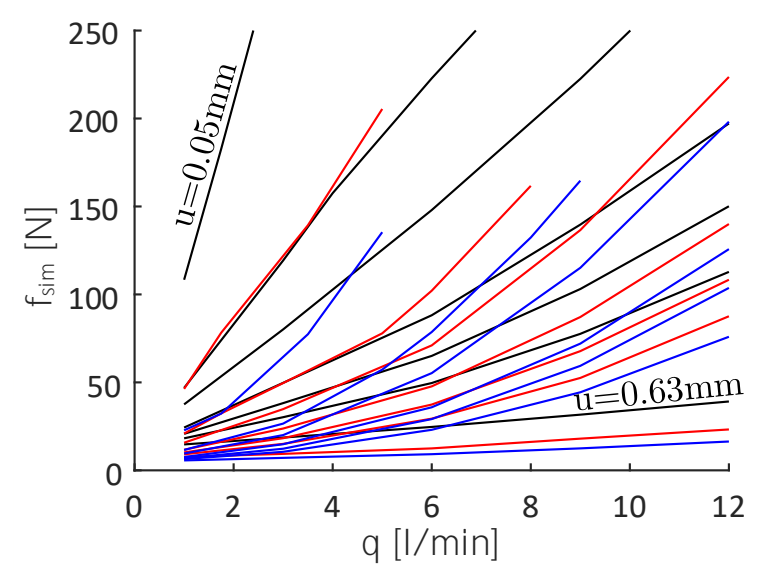

Figure 9: $f_{\text {sim }}(\mathrm{q})$ for $\mathrm{HV}$ at 20(black), 40(red), and $60^{\circ} \mathrm{C}$ (blue)

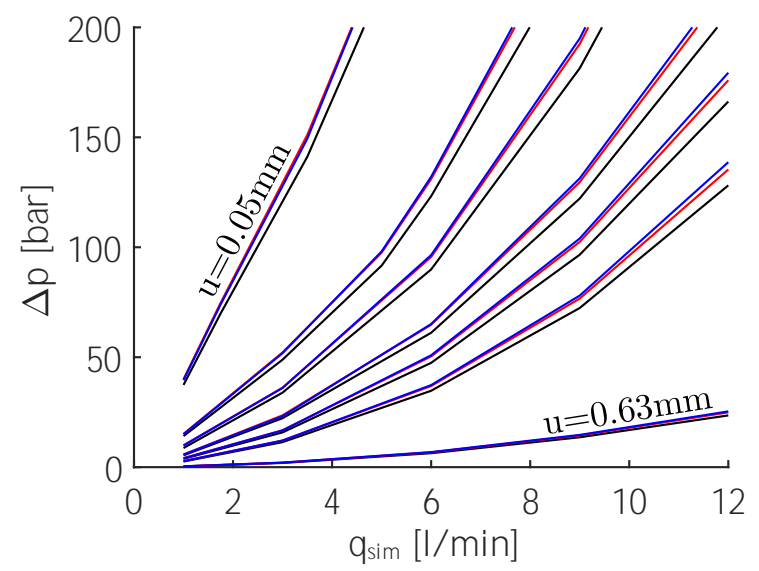

Figure 8: $\Delta p\left(q_{\text {sim }}\right)$ for HV(black) HEES(red) $\mathrm{HEES}+$ (blue) at $40^{\circ} \mathrm{C}$

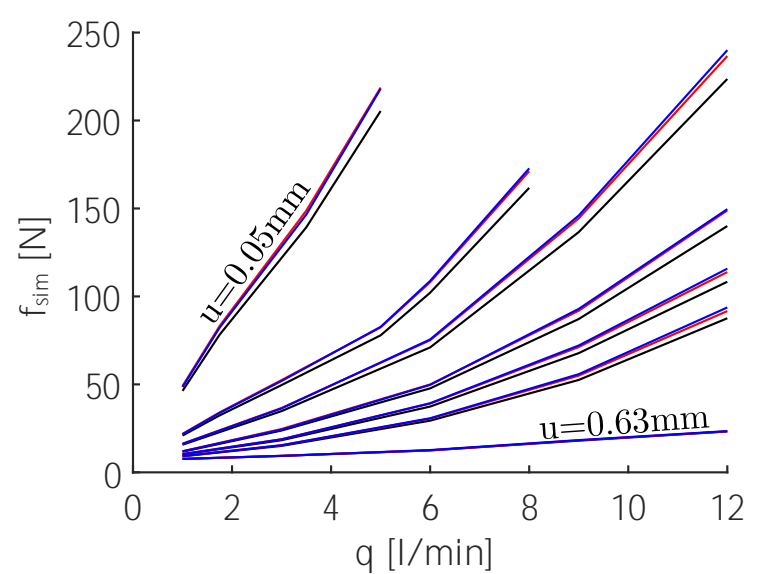

Figure 10: $f_{\text {sim }}(\mathrm{q})$ for HV(black) HEES(red) HEES+(blue) at $40^{\circ} \mathrm{C}$ 


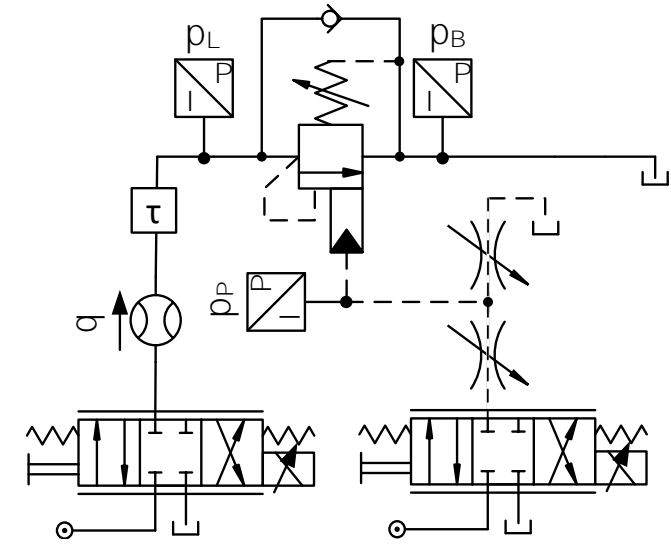

Figure 11: Hydraulic circuit

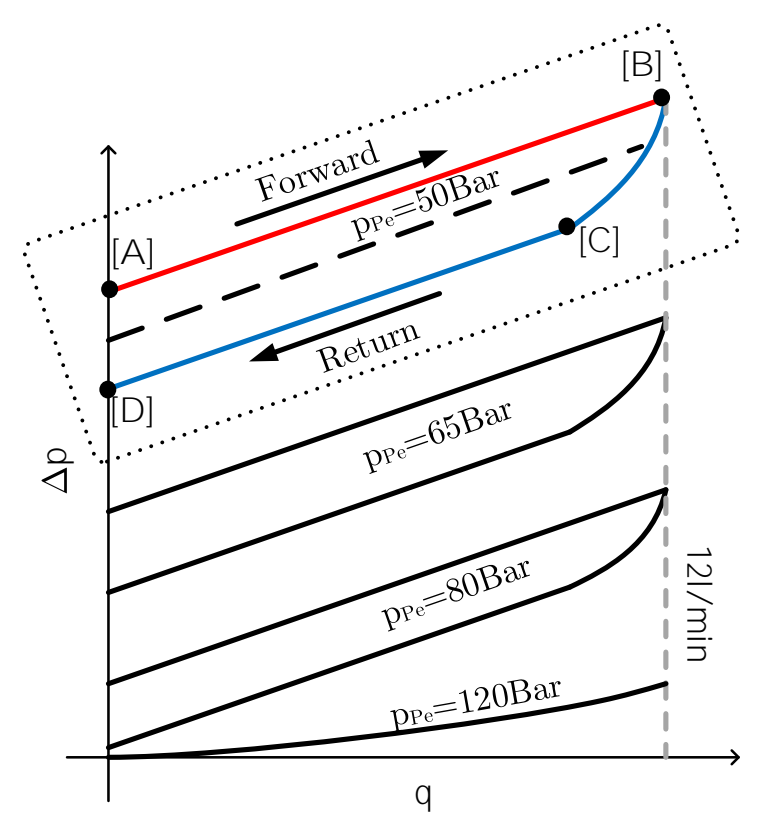

Figure 12: Sketch of typical CBV data. (point $[\mathrm{D}]$ ). At the beginning of the blue curve, near point $[\mathrm{B}]$, the friction is still similar to that of the forward curve, and that curves values are still above the no friction line. But as the flow further decreases the friction changes direction and the blue curve drops below the no friction line. The gradual friction change from $[\mathrm{B}]$ to $[\mathrm{C}]$ can be attributed to an intermediate state of friction while going from being fully developed Coulomb friction in one direction to being fully developed in another direction. At $p_{P e}=120$ bar the valve is forced fully open by the pilot pressure and the valve acts as a simple restriction with a fixed cross-section and the forward and return curves are therefore on top of each other. Looking at Figure 13 ( $\mathrm{HV}$ at $40^{\circ} \mathrm{C}$ ) the overall behavior is, except for a few notable differences, in accordance with the typical behavior depicted in Figure 12. Figure 13 also shows $\Delta p(\mathrm{q})$ curves from the CFD with u kept constant(red curves). It illustrates that the $\Delta p(\mathrm{q})$ curve for $\mathrm{u}=0.33 \mathrm{~mm}$ is very close to the $p_{P e}=80 \mathrm{bar}$ data for all values of $\mathrm{q}$, indicating that limited spool movement is needed to produce the $p_{P e}=80 \mathrm{bar}$ data set. The lack of hysteresis at the $p_{P e}=80$ bar data sets can, therefore, be explained by little or no spool movement and, subsequently, friction can be expected to be in a non-Coulomb state. It also shows that the $p_{P e}=50,65$ and 80bar data sets are mostly within $u \in[0.05 ; 0.33] \mathrm{mm}$, which makes that particular interval of $u$ values of special interest. This interval is therefore defined as the workspace of the valve. Figure 14 shows the data differences between the

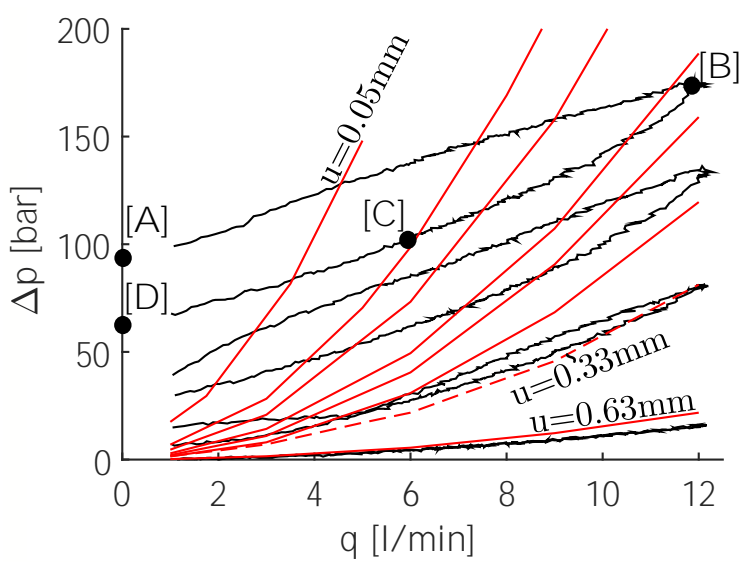

Figure 13: $\Delta p(\mathrm{q})$ for the $\mathrm{HV}$ data at $40^{\circ} \mathrm{C}$ (black). Simulated $\Delta p(\mathrm{q})$ for $u \in\{0.05,0.08,0.10$, $\left.0.13,0.16,0.20,0.33^{*}, 0.63\right\} \mathrm{mm}$ (Red). The $\mathrm{u}=0.33 \mathrm{~mm}$ curve is interpolated.

temperatures for HV. The figure shows steeper curves at low temperature indicating a more restrictive valve behavior, and the $\Delta p$ across the valve is significantly higher at low temperatures. The difference in $\Delta p$ be- 
tween $20^{\circ} \mathrm{C}$ and $60^{\circ} \mathrm{C}$ grows with $\mathrm{q}$ and end at $30 \%$ for $p_{P e}=50 \mathrm{bar}$ and $50 \%$ for $p_{P e}=80 \mathrm{bar}$.

The three oil types in Figure 15, 16 and 17 behave very similar in terms of curve shape and steepness, and they share the temperature trends of Figure 14. The main difference between the data of the different oils is hysteresis. The hysteresis of HEES+ is in some tests significantly less than HV and HEES significantly higher. The overall trends for hysteresis is, however, shared, and for all three oils, hysteresis grows with temperature and reduces with $p_{P e}$. Table 5 shows the maximum hysteresis for each data set measured as the maximum $\Delta p$ difference between the forward and the return curve at any q. The table shows that HEES has up to $23 \%$ higher hysteresis than HV and that HEES+ has up to $40 \%$ lower hysteresis.

Table 5: $\Delta \Delta p$ for 20,40 and $60^{\circ} \mathrm{C}$ for the $p_{P e}=50 \mathrm{bar}$, $p_{P e}=65 \mathrm{bar}$ and $p_{P e}=80 \mathrm{bar}$ data sets and all three oils.

\begin{tabular}{c|c|c|c|c|}
\cline { 3 - 5 } \multicolumn{1}{c|}{} & \multicolumn{3}{|c|}{$\tau\left[{ }^{\circ} \mathrm{C}\right]$} \\
\cline { 2 - 5 } \multicolumn{1}{c|}{} & 20 & 40 & 60 \\
\hline Oil type & $p_{P e}[\mathrm{bar}]$ & \multicolumn{3}{|c|}{$\Delta \Delta p[\mathrm{bar}]$} \\
\hline \multirow{3}{*}{$\mathrm{HV}$} & 50 & 42.7 & 37.9 & 27.5 \\
\cline { 2 - 5 } & 65 & 31.0 & 24.2 & 19.4 \\
\cline { 2 - 5 } & 80 & 12.6 & 8.7 & 5.7 \\
\hline \multirow{3}{*}{ HEES } & 50 & 51.9 & 37.8 & 29.3 \\
\cline { 2 - 5 } & 65 & 33.6 & 26.6 & 23.8 \\
\cline { 2 - 5 } & 80 & 15.0 & 9.2 & 8.2 \\
\hline \multirow{3}{*}{ HEES+ } & 50 & 33.5 & 22.8 & 19.4 \\
\cline { 2 - 5 } & 65 & 30.2 & 21.8 & 18.8 \\
\cline { 2 - 5 } & 80 & 15.8 & 9.5 & 8.1 \\
\hline
\end{tabular}

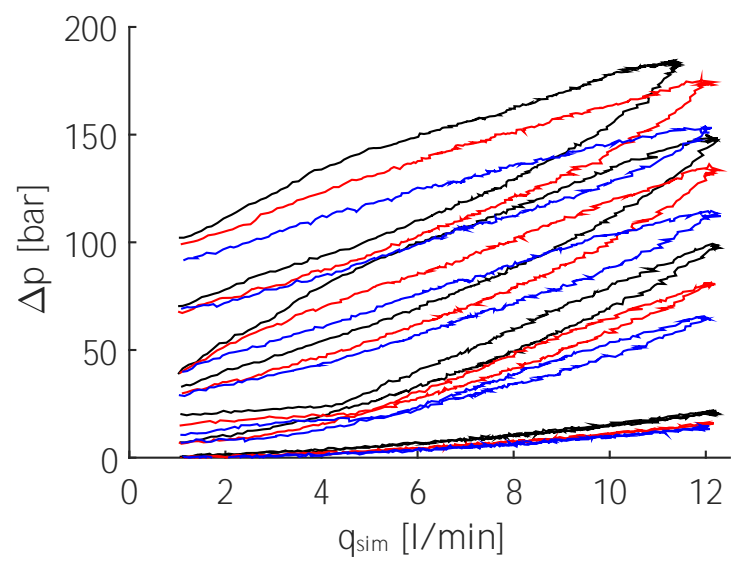

Figure 14: $\Delta p$ (q) for HV at 20(black), 40(red), and $60^{\circ} \mathrm{C}$ (blue).

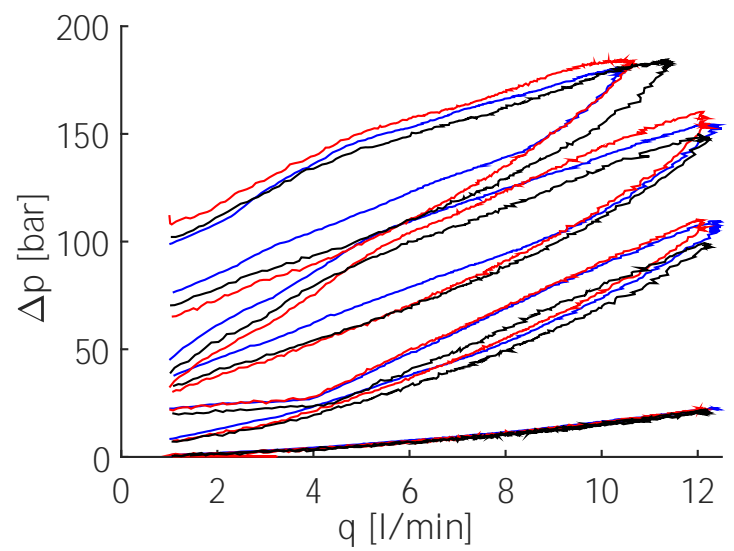

Figure 15: $\Delta p(\mathrm{q})$ for $\mathrm{HV}$ (black) HEES(red) HEES+(blue) at $20^{\circ} \mathrm{C}$.

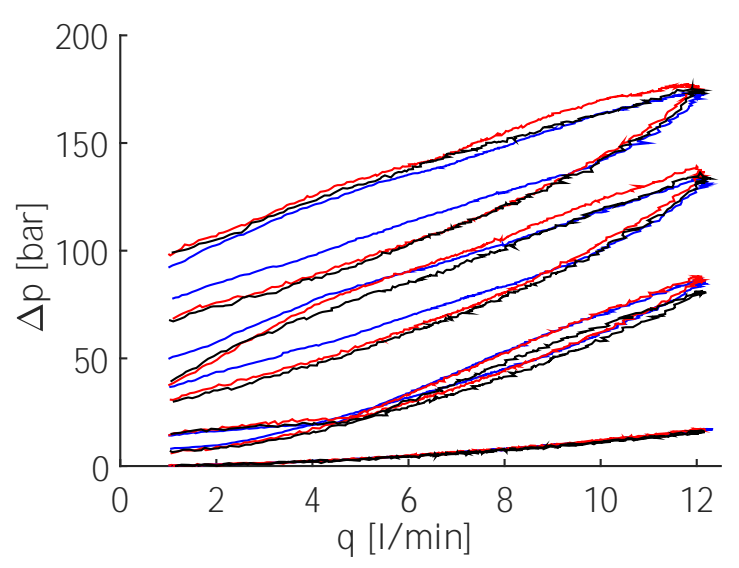

Figure 16: $\Delta p(\mathrm{q}) \quad$ for $\quad \mathrm{HV}($ black $) \quad$ HEES(red) HEES+(blue) at $40^{\circ} \mathrm{C}$.

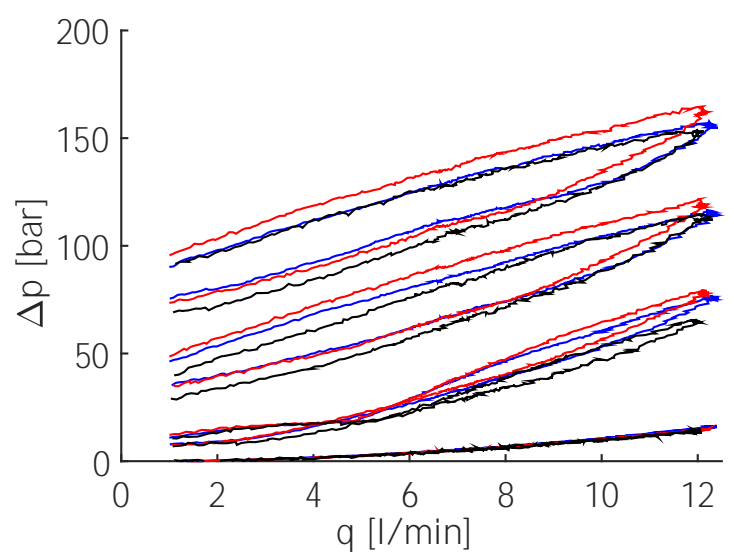

Figure 17: $\Delta p(\mathrm{q}) \quad$ for $\quad \mathrm{HV}($ black $)$

HEES(red) HEES+(blue) at $60^{\circ} \mathrm{C}$. 


\section{Results}

The valve model is fitted to the experimental data in two steps. The first step fits the model without friction components to a median curve, which represents a friction-free data set. The second step identifies the friction components and their dependency on the test-parameters in the experiment, $p_{P e}, \tau$ and $\gamma$. The two-step procedure allows for a separate evaluation of model components and their accuracy.

A friction free data set is needed in order to evaluate the model without friction. This is done by producing "friction free" median curves based on the actual data sets. The following assumptions about the friction are made to produce the median curves:

- The hysteresis is produced by friction.

- The fully developed friction is symmetric.

The Coulomb friction is, as mentioned in Section 2.1, not at perfect fit for the friction experienced by the CBV. Figure 18 shows 4 data sets where the flow is limited to $4,8,12$ and $14 \mathrm{~L} / \mathrm{min}$ at $p_{P e}=65$ bar. The returning curves of the different data sets, do not initially line up, and hysteresis slowly builds up, as the flow is reduced. This shows that the friction needs time or spool displacement before the build-up is complete. The hysteresis build-up of the $12 \mathrm{l} / \mathrm{min}$ data set used for the model comparisons is done at about $6 \mathrm{l} / \mathrm{min}$, and the hysteresis and friction from $6 \mathrm{l} / \mathrm{min}$ to $0 \mathrm{l} / \mathrm{min}$ is deemed to be fully developed (thick red curve on the return curve). A similar build-up is seen at the start of the forward curves, and a similar thick red curve can be drawn on the forward curve from $6 \mathrm{l} / \mathrm{min}$ to $12 \mathrm{l} / \mathrm{min}$. A correction of the data without Coulomb friction is then made by extrapolating from the red curves (Red dotted lines). The corrected data together with data with fully developed friction constitutes a full corrected data set with Coulomb friction. By assuming symmetric friction, a friction-free data set can be estimated as the average of the corrected forward and return curves. This average curve is called the median curve (Dashed grey curve). Note that since the $p_{P e}=80 \mathrm{bar}$ data set experience limited spool movement it is not possible to determine where the data might be fully developed, and the median curve is instead taken as the average of the uncorrected forward and return curve. Figure 19 shows the model without friction component for $\mathrm{HV}$ at $40^{\circ} \mathrm{C}$ plotted against data with the median curves of each data set. The model has been fitted to the $p_{P e}=65$ bar data set by scaling the $f_{\text {sim }}$ map by a factor of 1.02 . The model while not perfect demonstrate a reasonable accuracy and fits the median curves reasonably. The model is

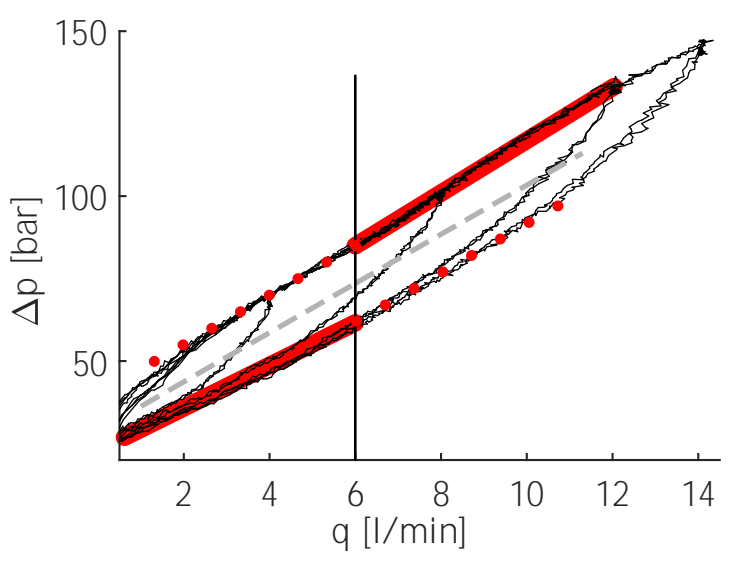

Figure 18: $p_{P e}(\mathrm{q})$ with $\mathrm{q}$ limited to $4,8,12$ and 14L/min (black). Median curve (dashed grey). Data with fully developed friction (red). Corrected data (dotted red).

off the median curve by less than 10bars on average for the $p_{P e}=50$ bar data set and less than 5bar for the $p_{P e}=65 \mathrm{bar}$ and $p_{P e}=80 \mathrm{bar}$ data sets. Table 6 is produced by fitting the model to the $40^{\circ} \mathrm{C} p_{P e}=65$ bar data set of each of three oil types and noting the accuracy. For all three oil types the best accuracy by scaling $q_{\text {sim }}, u_{\text {sim }}, f_{\text {sim }}$, and $\Delta p_{\text {sim }}$ in the CFD-maps was achieved by scaling $f_{\text {sim }}$ by $1.02,0.98$ and 0.98 for HV, HEES and HEES+, respectively.

In Table 6 for $\mathrm{HV} 20^{\circ} \mathrm{C}$ and $60^{\circ} \mathrm{C}$ show similar trends as $40^{\circ} \mathrm{C}$ but with slightly less accuracy. Table 6 also shows that the model accuracy for the esters is very similar to that of $\mathrm{HV}$ with only a few cells being of lower accuracy category.

It should be noted that the accuracy of the model was compared to a simpler model not based on CFD in Jakobsen and Hansen (2020) and was found significantly more accurate.

Table 6: Model accuracy. Accuracy is based on the average distance to the median curve and simplified into categories.

"-" less than 15bar from the median curve.

"+" less than 10bar from the median curve.

"++" less than 5bar from the median curve.

\begin{tabular}{|l|c|c|c|c|c|c|c|c|c|}
\hline$p_{P e}[\mathrm{bar}]$ & \multicolumn{3}{|c|}{50} & \multicolumn{3}{c|}{65} & \multicolumn{3}{c|}{80} \\
\hline$\tau\left[{ }^{\circ} \mathrm{C}\right]$ & 20 & 40 & 60 & 20 & 40 & 60 & 20 & 40 & 60 \\
\hline $\mathrm{HV}$ & ++ & + & - & ++ & + & - & ++ & + & + \\
\hline HEES & ++ & + & - & ++ & + & - & ++ & + & + \\
\hline HEES + & ++ & + & - & ++ & + & - & ++ & + & + \\
\hline
\end{tabular}

The main difference between the oils is identified in the data section to be the hysteresis. The hysteresis 


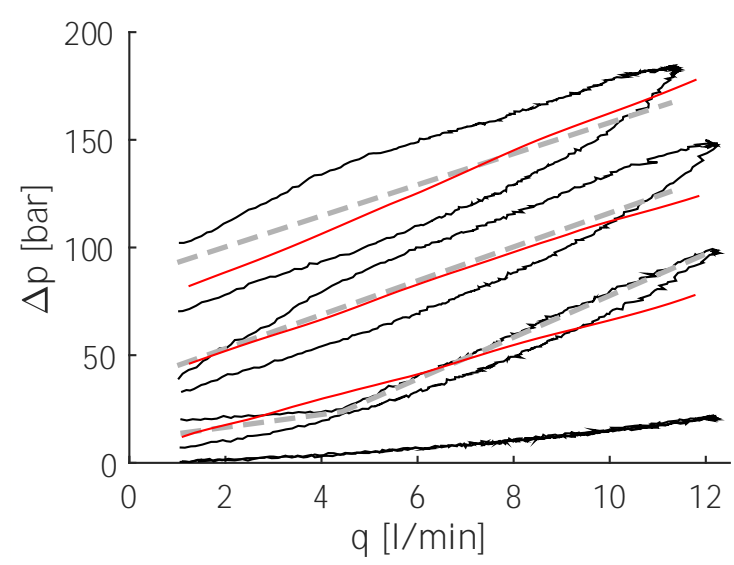

Figure 19: Model without friction(red), data(black), Median curve(gray) for $\mathrm{HV}$ at $40^{\circ} \mathrm{C}$.

is produced by friction and this section focuses on the friction dependency on $p_{P e}$, temperature and oil type. In order to identify the friction force needed to create the hysteresis, the fitted model with no friction component, described in the section above, is combined with a basic Coulomb friction model and fitted to the hysteresis of each data set.

Figure 20 shows the model with two friction fits for $\mathrm{HV}$ at $40^{\circ} \mathrm{C}$, one to $p_{P e}=50 \mathrm{bar}$ and one to $p_{P e}=65 \mathrm{bar}$. Table 7 contains the $p_{\mu 0}$ values fitted to each data set across temperature, $p_{P e}$ and oil type.

The model is fitted to match the hysteresis at $6 \mathrm{l} / \mathrm{min}$ to avoid the influence of the undeveloped friction. The table reflects the hysteresis data (Table 5) in that $f_{\mu 0}$ is generally higher for HEES and lower for HEES + and that $f_{\mu 0}$ is higher for lower $p_{P e}$ and lower temperature.

The friction variations depicted by the table are sig-

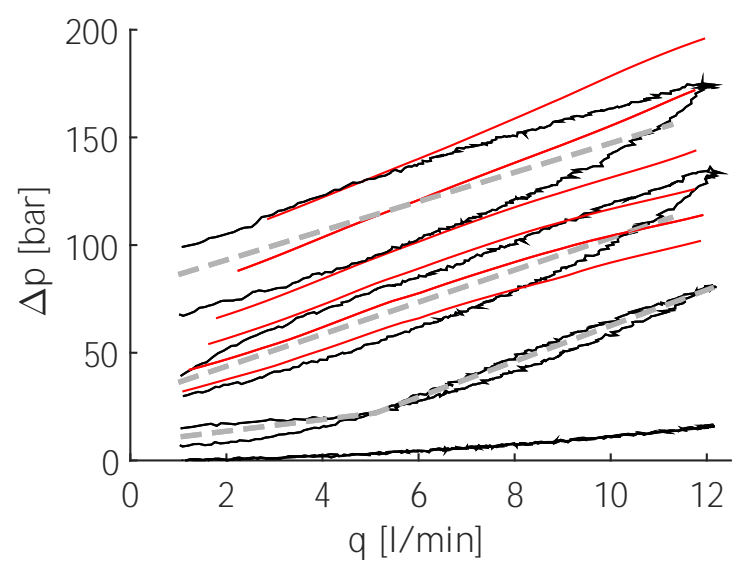

Figure 20: Model with friction(black), data(blue), Median curve(gray) for $\mathrm{HV}$ at $40^{\circ} \mathrm{C}$.

nificant and must be included in any accurate model, and all three parameters $\gamma, p_{P e}$ and $\tau$ have an apparent
Table 7: $f_{\mu 0}$ for 20,40 and $60^{\circ} \mathrm{C}$ for the $p_{P e}=50 \mathrm{bar}$ and $p_{P e}=65$ bar data sets and all three oils.

\begin{tabular}{l|c|c|c|c|}
\cline { 3 - 5 } \multicolumn{2}{c|}{} & \multicolumn{3}{c|}{$\tau\left[{ }^{\circ} C\right]$} \\
\cline { 2 - 5 } \multicolumn{1}{c|}{} & 20 & 40 & 60 \\
\hline \multirow{2}{*}{ Oil type } & $p_{P e}[\mathrm{bar}]$ & \multicolumn{3}{c|}{$f_{\mu 0}[\mathrm{~N}]$} \\
\hline \multirow{2}{*}{$\mathrm{HV}$} & 50 & 23.0 & 20.0 & 14.8 \\
\cline { 2 - 5 } & 65 & 16.6 & 11.0 & 9.5 \\
\hline \multirow{2}{*}{ HEES } & 50 & 26.9 & 19.1 & 15.0 \\
\cline { 2 - 5 } & 65 & 16.5 & 12.3 & 11.4 \\
\hline \multirow{2}{*}{ HEES+ } & 50 & 17.4 & 11.6 & 9.9 \\
\cline { 2 - 5 } & 65 & 14.6 & 9.5 & 9.0 \\
\hline
\end{tabular}

influence on the fitted Coulomb friction. The influence from the three parameters is handled by looking at the effects of $p_{P e}$ and $\tau$, and how $\gamma$ influences these two effects.

\subsection{Friction - Effective pilot pressure}

It is clear from looking at Table 7 that $f_{\mu 0}$ has some dependency on $p_{P e}$. Figure 21 investigates this relationship by showing $f_{\mu 0}$ normalized with $f_{\mu 0}$ at $p_{P e}=65$ bar plotted against temperature, $\alpha_{\text {ppe }}$.

$$
\alpha_{p p e}\left(\tau, p_{P e}, \gamma\right)=\frac{F_{\mu 0}\left(\tau, p_{P e}, \gamma\right)}{F_{\mu 0}(\tau, 65 b a r, \gamma)} .
$$

$\alpha_{\text {ppe }}$ differs significantly between oil types, suggesting

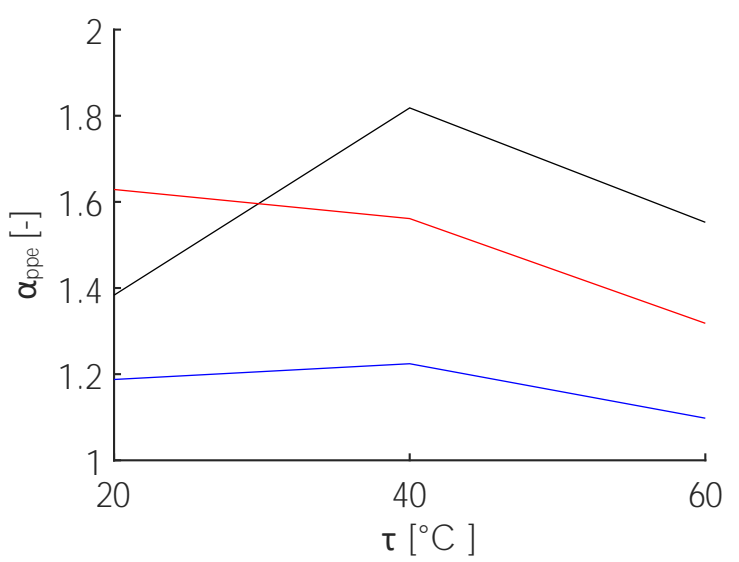

Figure 21: $\alpha_{\text {ppe }}$ as a function of temperature for all three oil types. HV(black), HEES(red), HEES+(blue). Note $\alpha_{p p e}$ for $p_{P e}=65$ bar is not shown since it is always 1

the relationship between $p_{P e}$ and $f_{\mu 0}$ would need to be determined for each separate oil type to get an accurate friction prediction. $\alpha_{p p e}$ also varies with temperature but for a given oil type the average across temperature is within $20 \%$ of the maximum range and could be used 
as a rough estimate for all temperatures. If the oil type is an ester then $\alpha_{p p e}$ is within $16 \%$ of $\alpha_{p p e}$ for that same ester at $40^{\circ} \mathrm{C}$.

\subsection{Friction - Temperature}

Table 7 shows that $f_{\mu 0}$ changes with temperature. Figure 22 shows the table values plotted as $\alpha_{\text {tau }}$ against temperature with one curve for each $p_{P e}$ and oil type. $\alpha_{\text {tau }}$ is $f_{\mu 0}$ normalized with $f_{\mu 0}$ at $40^{\circ} \mathrm{C}$.

$$
\alpha_{\tau}\left(\tau, p_{P e}, \gamma\right)=\frac{F_{\mu 0}\left(\tau, p_{P e}, \gamma\right)}{F_{\mu 0}\left(40^{\circ} C, p_{P e}, \gamma\right)} .
$$

All the data sets but the one with $\mathrm{HV}$ at $p_{P e}=50 \mathrm{bar}$ follow the same pattern; an increase between $35 \%$ and $54 \%$ when the temperature is lowered from $40^{\circ} \mathrm{C}$ to $20^{\circ} \mathrm{C}$ and a decrease between $6 \%$ and $22 \%$, when the temperature is raised from $40^{\circ} \mathrm{C}$ to $60^{\circ} \mathrm{C}$. Meaning that $\alpha_{t a u}$ is not strongly dependent on $p_{P e}$ and $\gamma$. For a given ester how can the hysteresis be predicted,

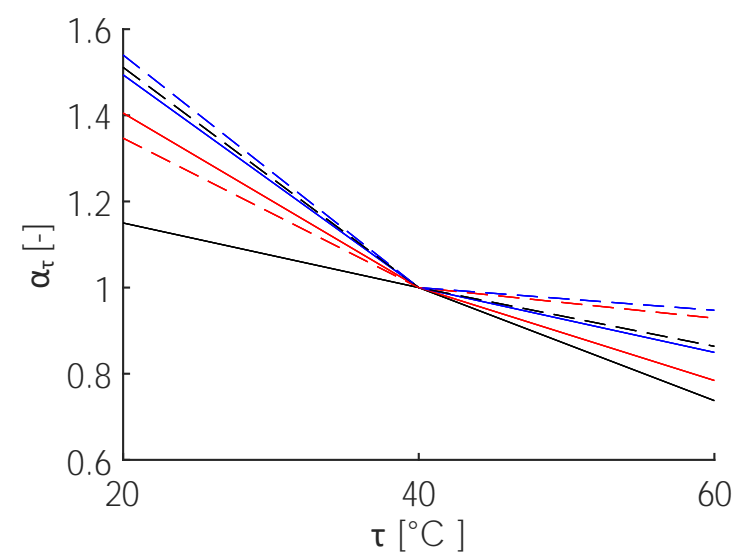

Figure 22: $f_{\mu 0}(\tau)$ relative to $f_{\mu 0}$ at $40^{\circ} \mathrm{C}$ for each oil. $\quad \mathrm{HV}$ at $p_{P e}=50 \mathrm{bar}$ (black), $\mathrm{HV}$ at $p_{P e}=65$ bar (black-dashed), HEES at $p_{P e}=50 \mathrm{bar}(\mathrm{red})$, HEES at $p_{P e}=65 \mathrm{bar}(\mathrm{red}-$ dashed), HEES+ at $p_{P e}=50$ bar(blue), HEES + at $p_{P e}=65$ bar (blue-dashed).

and what information is needed? Using the abovementioned patterns two suggestions are made eq.(14) and eq.(15). Hysteresis of the esters may be predicted from the behavior of $\mathrm{HV}$ at $p_{P e}=65$ bar and a single data set of the particular ester to within $29 \%$ of the actual value. This can be done by scaling the $f_{\mu 0}$, obtained from a single ester data set with the temperature averaged $\alpha_{\text {ppe }}$ for $\mathrm{HV}$ and $\alpha_{\tau}$ for $\mathrm{HV}$, (see (14)).

$$
\begin{array}{r}
f_{\mu 0 *}\left(\tau, p_{P e}, \gamma\right)=f_{\mu 0}\left(40^{\circ} C, 65 b a r, \gamma\right) \\
\cdot \alpha_{\tau}\left(\tau, p_{P e_{-} j}, \gamma_{k}\right) \cdot \bar{\alpha}_{p p e}\left(p_{P e}, H V\right) .
\end{array}
$$

Where $p_{P e_{-} j}$ is a specific $p_{P e}$ and $\gamma_{k}$ is a specific oil type. $f_{\mu 0}\left(40^{\circ} \mathrm{C}, 65 \mathrm{bar}, \gamma\right)$ is $f_{\mu 0}$ from a single data set at $40^{\circ} \mathrm{C}$ and $p_{P e}=65$ bar for the chosen oil type. The single data set is chosen based on the $p_{P e}$ and temperature in the normalization of $\alpha_{\text {ppe }}$ and $\alpha_{\tau}$. $\alpha_{\tau}\left(\tau, p_{P e_{-} j}, \gamma_{k}\right)$ is the relative change with temperature for any oil at any $p_{P e}$ except it cant be $\mathrm{HV}$ at $p_{P e}=50 \mathrm{bar}$ ( $\mathrm{HV}$ at $p_{P e}=65 \mathrm{bar}$ was chosen for the $29 \%$ calculation $). \bar{\alpha}_{p p e}\left(p_{P e_{-} j}, H V\right)$ is the temperature average of the change with $p_{P e}$ for $\mathrm{HV}$.

The accuracy of the predicted ester hysteresis can be further enhanced with the knowledge of the $f_{\mu 0}\left(p_{P e}\right)$ relationship of the ester oil to be predicted. If the $\alpha_{\text {ppe }}$ at $40^{\circ} \mathrm{C}$ for the esters are used instead of the temperature average value for $\mathrm{HV}$, then the predicted hysteresis is within $12 \%$ of the actual value:

$$
\begin{aligned}
& f_{\mu 0 *}\left(\tau, p_{P e}, \gamma\right)=f_{\mu 0}\left(40^{\circ} C, 65 b a r, \gamma\right) \\
& \cdot \alpha_{\tau}\left(\tau, p_{P e_{-} j}, \gamma_{k}\right) \cdot \alpha_{p p e}\left(40^{\circ} C, p_{P e}, \gamma\right)
\end{aligned}
$$

Where $\alpha_{p p e}\left(40^{\circ} C, p_{P e}, \gamma\right)$ is the relative change with $p_{P e}$ at $40^{\circ} \mathrm{C}$ for the oil to be predicted.

The results of using 15 to predict the friction of an oil is presented in figure 23. The resolution on

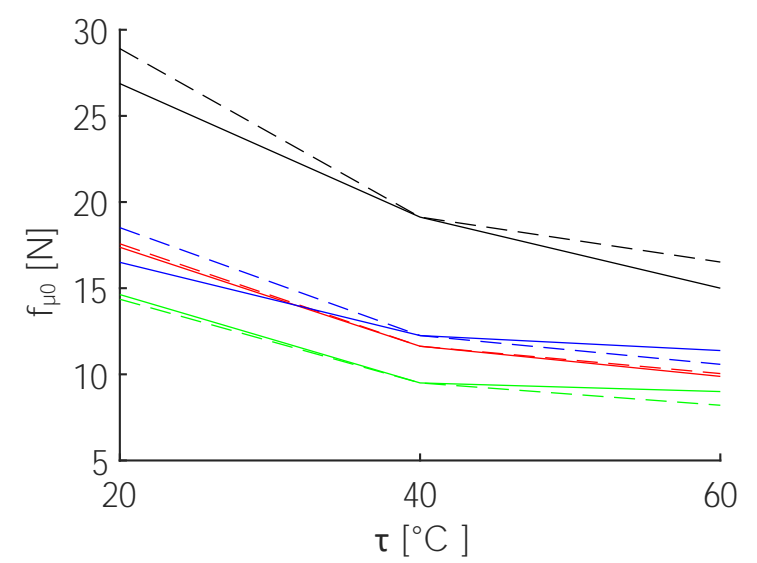
Figure 23: $f_{\mu 0}(\tau) \quad$ vs $\quad$ predicted $f_{\mu 0} *(\tau)($ dashed) using 15 for the two esters. HEES at $p_{P e}=50$ bar (black), HEES at $\quad p_{P e}=65$ bar(blue), HEES + at $p_{P e}=50 \mathrm{bar}(\mathrm{red}), \quad$ HEES + at $p_{P e}=65 \operatorname{bar}($ green $)$

$\alpha_{p p e}\left(p_{P e}\right)$ and $\alpha_{\tau}(\tau)$ with only three temperatures and two $p_{P e}$ data sets with Coulomb friction is limited, and it is insufficient, for identifying how many data sets (how much information) would be needed to make $\alpha_{p p e}\left(p_{P e}\right)$ and $\alpha_{\tau}(\tau)$ both continuous in $p_{P e}$ and $\tau$ and reasonably accurate. But by knowing the rough dependencies on $p_{P e}$ and $\tau$ experiments could be made to specifically target $\alpha_{p p e}\left(p_{P e}\right)$ and $\alpha_{\tau}$ 
and reduce the amount of necessary experimental work.

The HV $p_{P e}=50$ bar data sets are outliers as can be seen from Figure 22, and do not work for accurate prediction of the ester hysteresis. This poses a reliability issue for a generalization of the models. It would be impossible to know what $\mathrm{HV} p_{P e}$ data set could be used for the ester hysteresis estimation on another valve without a full test. More experimental work is therefore needed to determine the cause of the outliers, and to what extent the hysteresis prediction methods proposed can be generalized to other CBV valves.

\section{Conclusions}

The predicted fluid dynamics of esters and HV is similar, to the point that it can be argued that simulation for one oil covers the others. The choice between mineral oil and synthetic ester has a negligible effect on the simulated $C_{d}$, flow forces and ultimately the $q_{\text {sim }}$ and $f_{\text {sim }}$ maps.

Between the oil types there was a difference of $6 \%$ in density and $10 \%$ in viscosity (at $60^{\circ} \mathrm{C}$ ) and any oil within a similar density and viscosity range would yield similar results.

The main difference in CBV behavior between oil types is the hysteresis. The ester oil that differed the most from mineral oil was the saturated ester with up to $40 \%$ less hysteresis. The non-saturated ester had up $23 \%$ higher hysteresis than mineral oil.

A friction free steady-state model of valve behavior based on CFD was used to establish a base model with an average error within 10bar on $89 \%$ of the data sets corrected for non-Coulomb friction and within 15bar on all corrected data sets. The accuracy achieved for three oil types was very similar.

A simple Coulomb friction model was proposed to model the CBV friction and the resulting hysteresis of esters based on temperature, pilot pressure and oil type. The relationship between hysteresis and pilot pressure for the specific ester oil was needed to determine hysteresis with better than $29 \%$ accuracy. It was sufficient to determine the relationship between hysteresis and temperature for mineral oil, and the relationship for specific ester oil was not needed to get the predicted hysteresis within $12 \%$ of the data.

The data contained outliers which poses a reliability issue for a generalization of the oil type related prediction of hysteresis, and more experimental work would be needed before generalizing to other $\mathrm{CBV}$ valves.

\section{Acknowledgements}

The work is funded by the Norwegian Ministry of Education \& Research and Cameron Schlumberger.

\section{References}

Azushima, A., Xue, W., and Yoshida, Y. Influence of lubricant factors on coefficient of friction and clarification of lubrication mechanism in hot rolling. Isij International - ISIJ INT, 2009. 49:868-873. doi:10.2355/isijinternational.49.868.

Enekes, C. and Murrenhoff, H. How environmentally friendly tribological systems influence the efficiency of axial piston machines. Tribology Online, 2010. 5(5):245-249. doi:10.2474/trol.5.245.

Ferrari, A. Fluid dynamics of acoustic and hydrodynamic cavitation in hydraulic power systems. Proceedings of the Royal Society A: Mathematical, Physical and Engineering Sciences, 2017. 473(2199):20160345. doi:10.1098/rspa.2016.0345.

Handroos, H. and Halme, J. Semi-empirical model for a counter balance valve. Proceedings of the JFPS International Symposium on Fluid Power, 1996. 1996(3):525-530. doi:10.5739/isfp.1996.525.

Jakobsen, J. H. and Hansen, M. R. Synthetic esters and dynamics of pressure compensated proportional directional control valves. In Proc. of the 2018 Bath/ASME Symposium on Fluid Power and Motion Control. Bath, UK, 2018. doi:10.1115/FPMC20188933.

Jakobsen, J. H. and Hansen, M. R. Cfd assisted steady-state modelling of restrictive counterbalance valves. International Journal of Fluid Power, 2020. 21_1:119-146. doi:10.13052/ijfp1439-9776.2115.

Kržan, B. and Vizintin, J. Ester based lubricants derived from renewable resources. Tribology in Industry, 2004. 26:58-62.

Liu, J. and Bo Xie, H. Research on characteristics and key design parameters of a pilotassisted load control valve. Applied Mechanics and Materials, 2014. 541-542:1203-1210. doi:10.4028/www.scientific.net/AMM.541-542.1203.

Martins, R., Seabra, J., Brito, A., Seyfert, C., Luther, R., and Igartua, A. Friction coefficient in fzg gears lubricated with industrial gear oils: Biodegradable ester vs. mineral oil. Tribology International, 2006. 39(6):512 - 521. doi:10.1016/j.triboint.2005.03.021. 
Radhakrishnan, M. Hydraulic fluids A Guide to Se- Valdés, J. R., Rodríguez, J. M., Monge, R., Peña, J. C., lection, Test Methods, and Use. New York : ASME Press, 2003. doi:10.1115/1.801845.

Remmelmann, A. Die Entwicklung und Untersuchung von biologisch schnell abbaubaren Druckübertragungsmedien auf Basis von synthetischen Estern. Ph.D. thesis, Aachen, Techn. Hochsch., 1999.

Shell. Data Sheet - Shell Tellus S2 V4, 2013.

Statoil. Data Sheet - STATOIL HYDRAWAY BIO SE 46, 2013a.

Statoil. Data Sheet - STATOIL HYDRAWAY SE 46 HP, 2013b. and Pütz, T. Numerical simulation and experimental validation of the cavitating flow through a ball check valve. Energy Conversion and Management, 2014. 78:776 - 786. doi:10.1016/j.enconman.2013.11.038.

Zulkifli, N., Kalam, M., Masjuki, H., Shahabuddin, M., and Yunus, R. Wear prevention characteristics of a palm oil-based tmp (trimethylolpropane) ester as an engine lubricant. Energy, 2013. 54:167 - 173. doi:10.1016/j.energy.2013.01.038. 